\title{
iERBMF
}

\section{HIV/AIDS Prevalence as A Challenge for Sustainable Development: The Sub-Saharan Africa Experience}

\author{
Jamiu Adetola. Odugbesan ${ }^{1}$ and Husam Rjoub ${ }^{2}$ \\ ${ }^{1}$ Faculty of Economics and Administrative Sciences, Cyprus International University, North Cyprus. \\ ${ }^{2}$ Faculty of Economics and Administrative Sciences, Cyprus International University, North Cyprus.
}

\begin{abstract}
The study examined the sustainable development challenges from the Sub-Saharan Africa (SSA) perspective. Variables such as adjusted net saving (ANS) was employed as a proxy for sustainable development, while HIV/AIDS prevalence, human capital index, and good governance were employed as determinants factors for sustainable development. In the study, yearly data from 1990 to 2017 that was sourced from World Bank indicator, World Governance indicator, and Pen World Table were utilized and panel ARDL was employed for the analysis. The findings from the study reveal that there is a long-run causal relationship running from HIV/AIDS prevalence, human capital index, and good governance to sustainable development. The study in conclusion suggests that the region should intensify more efforts in ameliorating the prevalence of HIV/AIDS epidemic that has been ravaging the region. Also, the human capital potential should be harnessed, so as to contribute to the achievement of sustainable development. Moreover, the achievement of sustainable development in SSA region will be a mirage if the government of the countries within the region failed to improve on the governance.
\end{abstract}

Keywords: Sustainable development, Human capital, Good governance, Sub-Saharan Africa (SSA).

\section{Introduction}

It is not a gainsaying that the world is facing critical challenges in terms of sustainable development, most especially in the developing countries where on one side is the huge number of people that falls below the universal standard of living, despite the abundance of natural resources. And the other sides are significant social, economic, and environmental crises, which in most times snowballed into an epidemic and resulted in death (Milanovic, 2012; UNEP, 2012). The scenario, therefore, popped a question that in the case of Sub-Saharan Africa (SSA) where these challenges are obvious, how do we describe sustainable development and in what ways can it be achieved. 


\section{iERBMF}

There are several definitions of sustainable development in the literature; however, World Bank document posited sustainable development as a development path that requires monitoring and maintenance to ensure that the people's welfare does not diminish along the path (BotaAvram et al. 2018; Odugbesan and Rjoub, 2019). A significant point of reference in the course of sustainable development was the report published in 1987 by Brundtland commissions titled "Our Common Future" (Mignaqui, 2014). The report explained sustainable development as the principles jointly agreed to be put in place that will enable the present generation to go about satisfying their needs in such a way that it will not be detrimental to the ability of future generation to meet their own needs (Mignaqui, 2014).

Sustainable development is believed to have three dimensions that includes social, economic, and quality environment. To achieve sustainable development, these three dimensions must be fully and evenly integrated with the aim of enhancing development. In a recent study, the concept of sustainable development was criticized (Crowther and Seifi, 2016). The argument was that the concept is becoming irrelevant in the sustainable development achievement. It was further opined by the study that from the time Brundtland Report was released; the discussion on the report has been continuous in respect of development (Crowther, Seifi and Moyeen, 2018), in which the discussion has generated lots of confusion between sustainability and sustainable development. Meanwhile, the three dimensions of sustainable development (social, economic, and environment) are more pronounced in the literature, in spite of the fact that the Brundtland Report did not restrict the dimensions of sustainable development to those three, but also includes another dimension which is governance that has not been broadly considered. Whereas the achievement of sustainable development will be improved by effective governance, that abide with the rule of law, to ensure effective involvement of the citizen in decision making (Odugbesan and Rjoub, 2019).

Among the main challenge of achieving sustainable development in Africa as a whole is poverty eradication. This view was corroborated with the report of "African Ministerial statement" that was presented at the World summit on sustainable development (WSSD) which pointed it out that poverty needs to be eradicated in Africa in order for sustainable development to be achievable. The report posited that Africa remains the only continent where majority of the population lives below the world standard of living and lack access to basic necessity of lives. The report noted further that aside from being the poorest continent in the world, it is less technologically advanced, the least developed, region with high debts, high prevalence of food insecurity, and most marginalized. In addition, inadequate nutrition, environmental pollution, high prevalence of diseases (among which is HIV/AIDS), depletion of natural resources, inadequate and poor governance, are all significantly influence development in Africa. The situation in Africa is aggravated with the occurrence of natural disaster, and the HIV/AIDS epidemic that is ravaging the continent which constitutes a clog in the region's wheel of development, and putting a strain on the cost that becomes double of the cost in any other developing region with the consequence effect on the sustainable development of the region. 


\section{iEREMF}

The achievement of sustainable development is more achievable in an environment where good governance prevails, availability of peace and security, whereas the reverse is the case in Africa region where armed conflict is the order of the day. Moreover, Africa continent is known to be mostly fragmented region, with small and disaggregated economies that are at its disadvantage in the global development position. Despite the long-term allegiance by the African leaders on how to achieve regional integration, the process has been slow and thus becomes a challenge for the region. It is therefore not a gainsaying that sustainable development will be elusive in this part of the world if the concept is not properly conceptualized to proffer solution to the challenges impeding the achievement of sustainable development in the region.

\subsection{Economic dimension of Sustainable development}

This pillar of sustainable development is anchored on the Hick-Landahl model of the optimum flow of income which usually developed where good minimum number of assets is maintained that could yield benefits. The economic aspect of sustainable development is anchored on the concept of maximal and economic efficiency employed to the usage of limited resources. The implication of economic development on environmental pollution has been enunciated by the Environmental Kuznet Curve (EKC) hypothesis that emanated from Kuznet (1955) that study on the economic growth and income inequality discussion. The argument on the economic development and income inequality was that a country's environmental degradation is high when the level of income is low, while environmental pollution decreases when the level of income increases, which resulted in an inverted U-shaped relationship between environmental pollution and income level. The rationale behind this hypothesis is that as income improves which is as a result of economic growth, the people becomes conscious of the environment and begin to demand for products that will not be harmful to the environment. The relation of this hypothesis to SSA, it's obvious that the level of income in the region is low and the concomitant effect is on the environmental degradation. Whereas, looking at the sustainability from the economic dimension, the economic growth should be tailored towards eradicating poverty; sustenance of the resource base; non-absolute limits of technology; and, should be more energy efficient than in the past.

\subsection{Social dimension of Sustainable development}

The dimension is more of people's welfares, which seeks to maintain the social and cultural system stability, and also the amelioration of destructive conflicts (Wiebe, 2012). In this dimension, emphasis is placed on the equity. Cultural multifariousness and cultural capital preservation is important, and the good employment of knowledge that is related to sustainable practices implanted in a less-frequent culture is essential. There is need for the modern society to encourage bottom-top approach in decision making for socially sustainable development. Though, this dimension seems to be difficult to quantify, because socially sustainable development implies that there should be no social exclusion, everyone should have unrestricted access to good health care and a decent and affordable education. In a situation where there is 


\section{i[를}

social exclusion, and the people could not have access to good health care and decent affordable education, the negative influence takes its tolls on the human capital and the multiplier effect will be on the economy. Individuals with low education and inadequate health do have low efficiency. And for the social exclusion, the people excluded felt left-out, and this inclination offers ascent to clashes, political unrest, or even internal crisis. Meanwhile, where all these happened, the living condition in such region becomes deteriorated, health and education further diminishes considerably. This is the true scenario of the happenings in the SSA region, and so efforts must be sustained to achieve sustainable development in the region.

\subsection{Environmental dimension of Sustainable development}

The environmental perception of sustainable development is centering on the natural systems stability. Of particular significant is the viability of the system's units that are important to the world stability of the entire natural habitat. Moreover, the natural system may be contrived to include artificial environment like cities. The idea here is how the resilience and active ability of such systems can be preserved instead of an idea of conservation of the system in its static state. It is a known fact that natural resources depletion, pollution, and loss of natural environment decreases system resilience. Therefore, in respect to the environment in its relation to sustainable development, efforts should be to consider the bi-directional manners of human interaction with the nature. On one part is the resource exploitation, and on the other part is the emission into the nature. This aside the greenhouse gas (GHG) emissions, but other types of pollution such as nondecomposable materials and chemical waste.

The most significant issue in respect of environmental problem in SSA is that there is paucity of data that captured the problem. An author opined that the challenge is different for the individual countries in the region as a result of their climate zone, geographical location, and availability of natural resources deposit (Wiebe, 2012). For instance, the increasing desertification in the Saharan region and Kalahari Desert in Bostwana and Namibia, deforestation of the rain forest in the Central Africa countries, and the destructions of the environment by mining activities. All these problems as observed are on one hand difficult to appropriate in one variable and on the other hand differs across the countries (Wiebe, 2012). Hence the CO2 emissions and resource extraction data that is available for environmental indicator in SSA is not sufficient to capture the problem.

\subsection{Governance and Sustainable development}

Effective governance is necessary for sustainable economic change in less-developed countries. In any case, many developing countries at present don't have the farthest point, as opposed to the will, to both achieve and proceed with achieving good governance. In the absence of effective governance, the voyage for development is an unbeneficial objective. The non-attendance of good governance in an extraordinary piece of the developing scene has been appeared to adequately influence the development strategy. The non-effective governance has proved to be a 


\section{iERBMF}

determinant to various things such as, to undermine democracy, subverting the standard of law, prevalence of corruption, scare-off foreign investment and foreign aid, and prevents the execution of poverty alleviation and development approaches. It is of important that the improvement of the governance environment in the developing world should be a major priority on the development agenda and the capacity to do so must be enhanced (Hope, 2006).

Effective governance farthest point is fundamental for sustainable economic change in developing countries. Governance is about power, associations, and accountability from the people who have an effect on who picks, how inhabitants and various accomplices have their state, and how government are viewed as being concerned (Hope, 2009). The governance thought solidifies musings with respect to political leaders, the organization of economic and social resources, similarly as the utmost of governments is to characterize sound plans and play out their abilities in a convincing, capable, and fair-way.

At that point, there are different components of viewpoints on sustainable economic development and effective governance. Of noteworthiness to this examination is the point of view of Brautigam on governance and economy which described it as a neutral concept, implying that it is an act of having a political direction and exercised regulation over the activities of the citizens, societies, and states (Brautigam, 1991). The argument puts forward in the book was that the influence of effective governance on a country's economic development cannot be relegated to the background. In his perception, political accountability, effective rule of law, and transparency are among the critical elements of good governance that influence the economic growth. Good governance is viewed to be a new concept that identifies the duties of the state in the economy, where the involvement of the stakeholders is considered to be important in the sustainable development process (Bota-Avram et al. 2018). Stojanovic et al. (2016) opined that the central spot of development policy is occupied with the model of good governance, which has transformed into the establishment of development that is sustainable.

The association between governance and sustainable development got fantastic attentions from the researchers (Bota-Avram et al. 2018; Stojanovic et al. 2016). The composition on the relationship is mixed, as there are both opposing and supporting points of view on the issue. While some studies found that governance isn't a determinant factor for sustainable development (Bota-Avram et al. 2018), those studies that found relationship exists between governance and development opined that effective governance demand voice and accountability to the people and standard of law overseeing economic trades, regulatory quality, control of corruption, government ability to be effective, and a circumstance without war/conflict persecution. Various studies developed an association between sustainable economic development and effective governance (Bota-Avram et al. 2018; Leal Filho et al. 2016), while some exhibit no association between the two variables (Khan, 2007; Rodrik, 2008). Notwithstanding, the study of Stojanovic et al. (2016) revealed a quantifiable significance, direction, and importance of the effect of good governance, the examination, regardless, prescribed that there is no "one size fits all" model of good governance. In the context on the mixed results on the association between effective 


\section{iERBMF}

governance and sustainable development, it is significant to seek after the revelations of Stojanovic et al. and examine the association between effective governance and sustainable development in different regions.

\subsection{Research Method}

In line with the sustainable development model formulated by the World Bank, the analysis here follows the model which is presented as follows:

$\mathrm{ANS}=\mathrm{NNS}+\mathrm{E}-\mathrm{R}-\mathrm{P}$

Where, ANS = Adjusted net saving

NNS $=$ Net National Saving

$\mathrm{E}=$ Current education expenditure

$\mathrm{R}=$ Resource rents

$\mathrm{P}=$ Carbon dioxide $(\mathrm{CO} 2)$ damage

The model as employed in this study, current education expenditure is substituted for saving rather than consumption, because it improves the country's human capital, therefore human capital is employed as a proxy (Odugbesan and Rjoub, 2019). Pollution damages are more or less like a loss of welfare, which could be in form of human sickness, and as such HIV/AIDS prevalence was employed as a proxy (Odugbesan and Rjoub, 2019). As for the energy depletion which is the exploitation of oil, coal, and natural gas, this measure was viewed as the management of the natural resources, and as such, good governance was utilized as a proxy. The utilization of the variables in this study is in line with previous who had done similar studies and employed the variables. For instance, the adjusted net saving (ANS) was employed as a proxy for sustainable development in some previous studies (Gnegne, 2009; Lange et al; 2018; Nourry, 2008; Thiry and Cassiers, 2010). HIV/AIDS prevalence is the percentage of people aged between $15-49$ years old who are infected with HIV, while the good governance was measured with six indices which were computed into an index. The indices are voice and accountability, control of corruption, rule of law, government effectiveness, and political stability, regulatory quality, and absence of violence/terrorism. The index has been used by previous studies (BotaAvram et al. 2018; Stojanovic et al. 2016). And lastly, the human capital index from Penn World Table was utilized.

Meanwhile, the variables were derived from World Development Bank indicator (World Bank, 2018), Penn World Table (Feenstra et al. 2015), and World Governance Indicator (WGI, 2018). The data are annual data from 1990 - 2017, and it comprises of 26 Sub-Saharan Africa countries. The countries included in the study were subjected to the availability of data during the period observed. The data analysis was done using Pesaran et al., methodology. Pesaran et al, introduced an estimator called Pooled Mean Group (PMG) approach in panel Auto Regressive Distributive lag (ARDL) model (Pesaran, Shin and Smith, 1999). The model was found to have some edges ahead other panel estimator. Therefore, based on Pesaran et al., methodology, the 


\section{iERBMF}

panel ARDL model for this study including the long-run relationship between the variables and error correction term (ECT) is presented as follows:

$\Delta A N S_{i t}=\alpha_{i}+\sum_{j=1}^{p-1} \beta_{i j} \Delta A N S_{i, t-j}+\sum_{r=0}^{n-1} \gamma_{i r} \Delta H C I_{i, t-r}+\sum_{i=0}^{q-1} \varphi_{i l} \Delta H P R E V_{i, t-l}+\sum_{c=0}^{m-1} \tau_{i c} \Delta G G_{i, t-c}+$ $\delta_{1} A N S_{i, t-1}+\delta_{2} H C I_{i, t-1}+\delta_{3} H P R E V_{i, t-1}+\delta_{4} C L G_{i, t-1}+\varepsilon_{1 i, t}$

(1)

$\Delta A N S_{i t}=\alpha_{i}+\sum_{j=1}^{p-1} \beta_{i j} \Delta A N S_{i, t-j}+\sum_{i=0}^{q-1} \varphi_{i l} \Delta H C I_{i, t-l}+\sum_{r=0}^{n-1} \gamma_{i r} \Delta H P R E V_{i, t-r}+\sum_{c=0}^{m-1} \tau_{i c} \Delta G G_{i, t-c}+$ $a E C T_{t-1}+e_{1 i, t}(2)$

Where ANS, HPREV, HCI, and $G G$ are adjusted net saving (a proxy for sustainable development), HIV/AIDS prevalence rate, human capital index, and country level governance. $\Delta$ and $\sum k_{i t}(k=1,2,3,4)$ are the1st difference operator and a white noise term. Also, $\alpha_{1}$ denotes in (1), (2), (3) and (4), a country-specific intercept. The subscript $I$ denote a specific unit and is varying from 1 to $N$. The error term $e_{k i, t}(k=1,2,3,4)$ is independently and normally distributed with zero mean and constant variance, and $E C T_{t-1}$ is the error correction term specified from the long-run equilibrium relationship. The coefficient of $a$ shows the speed of adjustment to the equilibrium level in the presence of shock.

The robustness of the findings was enhanced by sub-divided the panel into sub-groups. This classification into sub-group (upper middle income -UMIC, low middle income - LMIC, and low income - LIC) was based on the 2018 World Bank country's classification according to level of economies.

\subsection{Findings and Discussion}

Prior to the analysis proper, pre-analysis such as unit root, cross-dependency test, and Cointegration analysis were done to ascertain the coefficients found from the analysis are sufficient, valid and free from any form of error, so as to ensure that the findings would be safe for making policy recommendation. The results found from the analysis on the unit-root test, indicates that the variables are mixture of variables that integrated on order (0) and order (1). This finding makes it safe to conclude that panel ARDL is appropriate for the analysis. As for the cross-dependency, the results show that there is no cross-dependency, the result shows that there is no cross-dependency issue in our data, while the Cointegration test which was estimated with Westerlund error correction model shows that long-run relationship exists among our variables (i.e ANS, HIV/AIDS prevalence, HCI, and GG).

\subsection{Improvement of the people's health}

The HIV/AIDS has been an issue for some time in SSA region, which was believed if not tamed, could reverse the gains of development in the region. The analysis was done to examine the relationship of this epidemic with sustainable development (ANS). The result as presented in Table 1 shows that in the long-run, there is a relationship between HIV/AIDS prevalence in SSA 


\section{iERBMF}

region and sustainable development. The coefficient is found to be statistically significant at $1 \%$ confidence level, which implies that the result is statistically established and safe to make policy recommendation. In order to ensure the robustness of the findings, the region was divided into sub-groups based on the World Bank 2018 countries' economies classification. The countries in the panel of our study show that three classes of economies were within the region (upper middle income, low middle income, and low income). The aim of the robustness test is to check if the result found for the group panel will be the same across the sub-groups.

However, from the result summarized in Table 1, the same result was found for upper-middle income and low-income countries, while the long-run relationship could not be established statistically for low-middle income countries. Meanwhile, the short-run relationship between sustainable development and HIV/AIDS prevalence could not be established, due to the nonsignificance of the coefficients of HIV/AIDS across the sub-groups of our analysis (Table 2). The outcome of the result is not surprising owing to the fact that, according to the literature, it takes some years (up to 6 years) for the HIV/AIDS to have a significant influence on the health status of the HIV/AIDS victims which will in turn affect the productive capacity of the people infected.

Moreover, the ECT coefficient (-0.50) shows that the model can converged back to equilibrium in case there is shock in the system. The result implies that in case there is shock from the external source to the system, the model will have converged back to the equilibrium at the speed of adjustment at about $50 \%$ rate. The implication of this result on the sustainable development is that, it shows the region's effort on the reduction of the epidemic in the region in yielding a positive result which shows in the low speed of convergence of the model. Therefore, the region should intensify more efforts on the programs and awareness targeted at reducing the prevalence of HIV/AIDS in the region.

\subsection{Harnessing Human capital potential}

The issue of human capital is significant to sustainable development of any region. This makes the variable to be included in the model and analyzed. The result as summarized and presented in table 1 indicates that there is a long-run relationship between the human capital and sustainable development, and the relationship is found to be statistically significant at 5\% confidence level. Though the coefficient is found to be negative, this is not surprising because it has been noted in the literature that human capital relationship with sustainable development is more of theoretical than empirical. To ascertain the veracity of the findings across the three levels of economies in the panel, the result as presented in table 1 reveals that the long-run relationship between human capital and sustainable development could not be statistically established due to its nonsignificance. However, while low-income countries have same negative long-run relationship between human capital and sustainable development as same with the group panel, the relationship was found to be positive and statistically significant low low-middle income countries. The short-run estimates (table 2) shows no relationship between human capital and 


\section{iEREMF}

sustainable development. However, the ECT coefficient (-0.50) that is statistically significant indicates that the model can converged to equilibrium in case of any external shock to the system The (-0.50) ECT coefficient implies that the model which includes human capital as a determinant of sustainable development has about 50\% speed of adjustment in case of any external shock. The robustness check result across the three sub-groups in the panel indicates that the finding is the same for all the countries in the panel irrespective of their level of economy.

The implication of this finding is that, the SSA countries have not adequately harnessed the potentials of human capital to contribute positively to the sustainable development of the region. To ensure sustainability in SSA region, the expenditure on the education to improve human capital development needs to be enhanced. The region is populated but the people need to be empowered to be able to contribute significantly to the sustainable development of the region. Otherwise, as the study finding reveals, the human capital in the region is not improved, it will influence negatively the achievement of sustainable development in the region.

\subsection{Governance improvement}

The issue of governance has been a neglected dimension of sustainable development, whereas, the achievement of sustainable development without a good and efficient governance, will be a mirage. The variable was included in our model to determine the contributing factors to the sustainable development in SSA region, both at the short and long-run. The result as summarized in Table 1, shows that good governance is found to have a positive causal influence on sustainable development at the long-run. The result was found to be statistically significant, and the robustness check of the result across the 3 sub-groups reveals that the result is the same across the sub-groups as they all shows a positive long-run relationship between good governance and sustainable development. Meanwhile, the analysis result as presented in Table 2 shows that there is no short-run relationship between good governance and sustainable development in the SSA region, also across the sub-groups. However, the joint causality of the variable together with other variables as they influence sustainable development indicates that they all have significant influence on the sustainable development. And in case of any external shock, the model can have converged back to the equilibrium at about $50 \%$ speed of adjustment.

The implication of our finding is that in the long-run, good governance will influence positively the sustainable development in SSA region. Sustainable development in SSA region will be a mirage in the absence of good governance. Good governance is found among other factors that will ensure the efficient utilization of the resources to promote development in the region, improves citizen participation, to make the government to be more responsible and accountable to the people, and this has the potential of poverty reduction in the region. It is imperative to note that any exploits to improve the people's welfare and sustain development in SSA region should be predicated on good governance. For sustainable development to be achieved in SSA region there is need for the government of the countries in the region to formulate policies that will 
remove the capacity hindrance that is presently constrained sustainable development in the region. For instance, the budgetary resources allocated for a particular purpose should be judiciously spent for the purpose earmarked it for instead of diverting it for personal use as it is being presently practiced in many SSA countries.

Good governance from all perspective has been shown to have positive relationship with sustainable development achievement, particularly through the establishment of an institution that promotes transparency, accountability and prudent public financial management. Our finding lends credence to the hypothesis of a positive relationship between good governance and sustainable development. However, the situation presently in the SSA region, some of the countries has a very weak capacity for sustaining good governance, and there is need for these to be developed.

Table 1. Long-run causality estimates

\begin{tabular}{|l|l|l|l|l|}
\hline & & \multicolumn{3}{|c|}{ Independent variables } \\
\hline & DEP. VAR. & $\Delta$ HIVPREV & $\Delta$ HCI & $\Delta$ GG \\
\hline Group Panel & $\Delta$ ANS & $1.12 *(0.32)$ & $-10.05^{* *}(4.28$ & $11.11^{*}(2.50)$ \\
\hline UMIC & $\Delta$ ANS & $1.70^{* *(0.77)}$ & $-7.33(7.85)$ & $16.21^{* * *(9.17)}$ \\
\hline LMIC & $\Delta$ ANS & $-1.04(0.65)$ & $37.06^{*}(10.09)$ & $22.41^{* *(7.86)}$ \\
\hline LIC & $\Delta$ ANS & $1.24 *(0.38)$ & $-10.17^{* * *}(5.72)$ & $9.90^{*}(2.75)$ \\
\hline
\end{tabular}

$*$, **, *** indicates $1 \%, 5 \%$ and $10 \%$ significance level respectively

Values in parentheses are standard error

$\mathrm{UMIC}=$ Upper middle income countries, LMIC = Low middle income countries, LIC = low income countries

Table 2. Short-run estimates (Joint causality)

\begin{tabular}{|l|l|l|l|l|l|}
\hline & & \multicolumn{3}{|c|}{ Independent variables } & \\
\hline & DEP. VAR. & $\Delta$ HIVPREV & $\Delta$ HCI & $\Delta$ GG & ECT(-1) \\
\hline $\begin{array}{l}\text { Group } \\
\text { Panel }\end{array}$ & $\Delta$ ANS & $9.82(10.16)$ & $12.22(38.54)$ & $0.94(3.04)$ & $-0.50^{*}$ \\
\hline UMIC & $\Delta$ ANS & $-1.75(3.31)$ & $37.96(62.63)$ & $4.81(4.01)$ & $-0.43^{* *}$ \\
\hline LMIC & $\Delta$ ANS & $38.28(33.90)$ & $-66.22(41.21)$ & $-5.98(8.06)$ & $-0.53^{*}$ \\
\hline LIC & $\Delta$ ANS & $0.01(3.56)$ & $39.80(55.81)$ & $1.11(3.53)$ & $-0.52^{*}$ \\
\hline
\end{tabular}

$*, * *, * * *$ indicates $1 \%, 5 \%$ and $10 \%$ significance level respectively

Values in parentheses are standard error

$\mathrm{UMIC}=$ Upper middle income countries, LMIC $=$ Low middle income countries, LIC $=$ low income countries 


\section{Conclusion}

The SSA region is lacking behind in the achievement of sustainable development as compared to other regions in the world. This study includes variables like HIV/AIDS prevalence that has been a challenging epidemic to the region in the model. "Health is wealth" as the saying goes, and a healthy society is a productive society. The government in the SSA countries needs to formulate more proactive policies and intensify more efforts to sustain the efforts in ameliorating the challenges of the epidemic in the region so that sustainable development could be achieved in the long-run.

As for the human capital, from our findings, there is need for the government of the SSA countries to harness the potentials of human capital in contributing to the achievement of sustainable development in the region. Policies that will be targeted at the improvement of human capacity should be of priority to the countries government. This is found to be one of the pre-requisites for achieving sustainable development in the region.

Lastly, the government in the SSA countries needs to consider good governance as an important factor in achieving sustainable development. As it was revealed in the literature and corroborated by our findings, bad governance will influence negatively on the achievement of sustainable development, while good governance will contribute positively to the achievement of sustainable development in the long-run. Therefore, the government should pursue an institutional capacity building policy that will enhance the governance which will in turn contribute to the development of the region. The region should also try to maintain a peaceful environment that will ensure peace and tranquility, because aside other known challenges in the region, violence and terrorism has been an order in the region.

\section{Acknowledgment}

The authors acknowledged that this article is the output of their research, with no conflict of interest.

\section{References}

[1] Boţa-Avram, C., Groşanu, A., Răchişan, P. R., \& Gavriletea, M. D. (2018). The Bidirectional Causality between Country-Level Governance, Economic Growth and Sustainable Development: A Cross-Country Data Analysis. Sustainability, 10(2), 502.

[2] Brautigam, D. Governance and Economy: A Review; World Bank Publications: Washington, DC, USA, 1991; Volume 815. 


\section{iER日）}

[3] Crowther, D., \& Seifi, S. (2016). The flawed logic of sustainable development. In K. Caliyurt \& U. Yuksel (Eds.), Sustainability and management: An international perspective (pp. 11-27). London: Routledge.

[4] Crowther, D., Seifi, S., \& Moyeen, A. (2018). Responsibility and governance in achieving sustainability. In The Goals of Sustainable Development (pp. 1-15). Springer, Singapore.

[5] Feenstra, Robert C., Robert Inklaar and Marcel P. Timmer (2015), "The Next Generation of the Penn World Table" American Economic Review, 105(10), 3150-3182, available at www.ggdc.net/pwt

[6] Gnègnè, Y. (2009). Adjusted net saving and welfare change. Ecological Economics, 68(4), 1127-1139.

[7] Hope, K. R. (2006). Capacity development and good governance. In A. S. Huque \& H. Zafarullah (Eds.), International Development Governance (pp. 587-598). Boca Raton, FL: CRC Press/Taylor \& Francis Group.

[8] Hope, K.R. (2009) Capacity Development for Good Governance in Developing Countries: Some Lessons from the Field, Intl Journal of Public Administration, 32:8, 728-740, DOI: 10.1080/01900690902908562

[9] Khan, M.H. Governance, Economic Growth and Development Since the 1960s; UNDESA Working Paper No. 54, ST/ESA/2007/DWP/54; UNDESA: New York, NY, USA, 2007.

[10] Lange, G. M., Wodon, Q., \& Carey, K. (Eds.). (2018). The changing wealth of nations 2018: Building a sustainable future. The World Bank.

[11] Leal Filho, W., Platje, J., Gerstlberger, W., Ciegis, R., Kääriä, J., Klavins, M., \& Kliucininkas, L. (2016). The role of governance in realising the transition towards sustainable societies. Journal of Cleaner Production, 113, 755-766.

[12] Mignaqui, V. (2014). Sustainable development as a goal: social, environmental and economic dimensions. International Journal of Social Quality, 4(1), 57-77.

[13] Milanovic, B. (2012). Global inequality recalculated and updated: the effect of new PPP estimates on global inequality and 2005 estimates. The Journal of Economic Inequality, 10(1), 1-18. 


\section{i[REMF}

[14] Nourry, M. (2008). Measuring sustainable development: Some empirical evidence for France from eight alternative indicators. Ecological economics, 67(3), 441-456.

[15] Odugbesan, J. A., \& Rjoub, H. (2019). Relationship among HIV/AIDS Prevalence, Human Capital, Good Governance, and Sustainable Development: Empirical Evidence from Sub-Saharan Africa. Sustainability, 11(5), 1348.

[16] Pesaran, M.H., Y. Shin, and R.J. Smith (1999). "Pooled mean group estimation of dynamic heterogeneous panels". Journal of American Statistical Association 94(446), pp. 621-634.

[17] Rodrik, D. (2008). Thinking about Governance. In Governance, Growth and Development Decision-Making; North, D.C., Daron, A., Francis, F., Dani, R., Eds.; The World Bank: Washington, DC, USA.

[18] Stojanović, I., Ateljević, J., \& Stević, R. S. (2016). Good governance as a tool of sustainable development. European Journal of Sustainable Development, 5(4), 558-558.

[19] Thiry, G., \& Cassiers, I. (2010). Alternative indicators to GDP: values behind numbers. Adjusted net savings in question. Applied Research in Quality of life, 23.

[20] UNEP (United Nations Environment Programme). 2012. Global Environment Outlook: Environment for the Future We Want - GE05. Nairobi: UNEP

[21] Wiebe, K. S. (2012). Quantitative assessment of sustainable development and growth in Sub-Saharan Africa. Maastricht University. https://cris.maastrichtuniversity.nl/portal/en/publications

[22] Wilson, R. (2016). Does governance cause growth? Evidence from China. World Development, 79, 138-151.

[23] World Bank (2018). World Band Development Indicators. http://databank.worldbank.org/data/home.aspx

[24] World Governance Indicators (2018). www.govindicators.org 